\title{
Del crimen al amor ${ }^{*}$
}

Fecha de recepción: 8 de mayo de 2014

Fecha de aprobación: 24 de septiembre de 2014

\section{Resumen:}

Este ensayo ofrece un análisis de la adaptación al cine de la novela La Virgen de los sicarios de Fernando Vallejo que hace Barbet Schroeder en el año 2000. Se demuestra cómo, a través de un sutil proceso de supresión, atenuación y/o realce de elementos fundamentales a la novela, esta adaptación resulta en un filme en el que se advierte un proyecto ético-estético diferente al del texto original y en algunos aspectos opuesto a este. Ello a pesar de que los contenidos diegéticos son bastante similares. Gracias a este proceso, el filme resulta menos abrumador que la novela.

Palabras clave: Literatura y cine; La Virgen de los sicarios; Literatura, cine y violencia; Fernando Vallejo; Cine y sicariato; Novela de sicarios.

* Este artículo está enmarcado en la investigación Violencia del narcotráfico y el sicariato en la novela colombiana, que inicié en la Universidad del Valle para el período 15-01-2006 / 15-06-2008 con el código CI-4213, y que continué durante mis estudios doctorales (adelantados con una comisión de estudios de la Univalle y con un crédito beca de Colfuturo) entre el 2008 y el 2012. Productos de esta investigación son además algunos ensayos publicados en revistas académicas, la tesis Novela y violencia en Colombia: el narcotráfico y el sicariato (que obtuvo el premio Gutiérrez Mañé a la mejor tesis doctoral del año sobre literaturas latinoamericanas y del Caribe hispánico en el Ph.D. Program in Hispanic and Luso-Brazilian Literatures and Languages del Graduate Center (CUNY), New York 2013), el libro La Virgen de los sicarios y la novela del sicario en Colombia (que ganó el premio de ensayo Autores Vallecaucanos Jorge Isaacs, Cali 2013) y el libro El narcotráfico en la novela colombiana (Univalle, 2013).

Citar: Osorio, Ó. (enero-junio de 2015). Del crimen al amor. La Palabra (26). Páginas 59-71

\section{Óscar Osorio}

Universidad del Valle, Colombia oscar.osorio@correounivalle. edu.co

Profesor Titular de la Universidad del Valle. Ph.D in Hispanic and LusoBrazilian Literatures and Laguage of The Graduate Center, City University of New York (CUNY). oscoso@hotmail.com 


\title{
From Crime to Love
}

\begin{abstract}
This essay offers an analysis of the film adaptation of the novel La Virgen de los Sicarios by Fernando Vallejo that Barbet Schroeder directs in the year 2000. It is shown how, through a subtle process of suppression, attenuation and/or highlighting of the fundamental elements to the novel, this adaptation results in a film in which we can see an ethical-aesthetic project different from the original text and sometimes in opposition to it, despite the fact that the diegetic contents are very similar. Because of this process, the film turns out to be less overwhelming than the novel.
\end{abstract}

Key words: Literature and film; La Virgen de los Sicarios; Literature, film and violence; Fernando Vallejo; Film and contract killers; "Sicario" novels.

\section{Du crime à l'amour}

\section{Résumé}

Cet essai offre une analyse de l'adaptation au cinéma, du roman La Vierge des tueurs de Fernando Vallejo, faite par Barbet Schroeder à l'an 2000. On démontre comment, à travers un subtile processus de suppression, nuance et/ou relief des éléments fondamentaux du roman, cette adaptation-là devient, d'un côté, un film dans lequel on constate un projet éthique-esthétique, différent du texte original ; et de l'autre côté, quelques aspects opposés au texte original. Cela, malgré le fait que les contenus diégétiques sont assez similaires. Grace à ce processus, le film est moins accablant que le roman.

Mots clés: Littérature et cinéma; La Vierge des tueurs; Littérature, cinéma et violence; Fernando Vallejo; Cinéma et tuerie; Roman de tueurs. 
La Virgen de los sicarios, dirigida por Barbet Schroeder en el 2000, es una adaptación de la novela homónima de Fernando Vallejo (1994). El texto fílmico, con guion del mismo Vallejo, es, a juicio de la mayoría de críticos, fiel al texto literario. A primera vista, el espectador se queda con la impresión que el filme es una repetición, que "es una adaptación bastante fidedigna de la novela de Vallejo" (Jácome, 2006, p. 153), un logrado esfuerzo de trasladar al formato fílmico el texto literario. Esta impresión se debe a una serie de correspondencias muy fieles entre los diálogos, los desplazamientos de los actores por la ciudad, los encuentros de Fernando con sus amantes, los crímenes que los sicarios cometen y las circunstancias en las cuales mueren estos, y las frases sentenciosas del narrador protagonista. En palabras de Edwin Carvajal: "La obra cinematográfica va captando paulatinamente las partes centrales de la obra, como una especie de sumario que va a plasmar con minuciosidad los acontecimientos o partes constitutivas del hecho literario" (2004, p. 57). Sin embargo, una lectura comparativa de los dos textos permite concluir que la adaptación fílmica es un proceso de atenuación, supresión o realce de elementos sustanciales de la novela y que dichas variaciones generan una transformación que destruye en lo fundamental la propuesta estética y la dimensión ideológica del texto literario, que la adaptación opera como un cedazo éticoestético que produce un texto, no solamente distinto, sino, en algunos aspectos, opuesto al original. ${ }^{1}$

\section{Estructura cíclica}

La diégesis es coincidente, en lo fundamental, en los dos textos y se conserva la estructura de repetición de las historias centrales: la historia Fernando-Wílmar es una duplicación de la historia Fernando-Alexis. Sin embargo, en la novela se desarrollan unos procedimientos textuales para profundizar esta repetición diegética que no están en el filme: el día en el cual Fernando salió del apartamento y entró a la iglesia de La América a pedirle "al Todopoderoso que puesto que no me mandaba la muerte me devolviera a Alexis" (p. 90), Fernando se encontró con Wílmar. Es decir, Dios le cumplió el deseo a Fernando devolviéndole a Alexis en Wílmar. Ese mismo día fueron a la iglesia de San Antonio y, a la salida de esta iglesia, Fernando leyó "bajo el reloj detenido" (p. 93) una sentencia en latín. Esto constituye otra simetría: con Alexis entra al "templo de las mariposas" donde los relojes están parados y con Wílmar entra al templo de San Antonio donde el reloj también lo está. Es decir, Fernando entra por su relación con los dos amantes en la intemporalidad. En varias ocasiones, Fernando se refiere a Wílmar como si este fuera Alexis (pp. 92, 95); cuando Wílmar se desvistió para Fernando la primera vez se le cayó un revólver (p. 94), igual que se le había caído a Alexis la primera vez que se desnudó para Fernando (p. 15) y en las dos ocasiones Fernando relaciona el revólver con una hipotética muerte suya y llama a su amante de turno de la misma manera: "Ángel de la guarda” (pp. 12, 94); durante el viaje a Sabaneta con Wílmar lo atrapa la nostalgia y recuerda cuando corría con sus hermanos, "felices, inconscientes, despilfarrando el chorro de nuestras vidas pasábamos frente a Bombay persiguiendo un globo" (p. 97), que es exactamente la misma escena que recuerda cuando pasó por Bombay en su primer viaje a Sabaneta con Alexis, y que es la escena que abre la novela

1 No se me escapa que los soportes expresivos de la novela y los del cine implican modelizaciones diferentes y que, por ello, muchas de las transformaciones surgidas en el proceso de adaptación son exigencias del lenguaje cinematográfico. (Debo esta precisión al profesor Alejandro López.) Sin embargo, la mayoría de los cambios que señalo en este trabajo obedecen a la intencionalidad trazada por un proyecto estético y ético para el texto fílmico que se distancia ampliamente del proyecto ético-estético que en el que se inscribe la novela. En cualquier caso, estos cambios, sean intencionales o imposiciones del lenguaje cinematográfico, son sustanciales y transforman radicalmente el texto original. 
y cierra la primera secuencia; cuando lleva a Wílmar al apartamento, este se extraña, como lo hizo Alexis cuando entró al mismo apartamento, porque no había música (pp. 17, 93); cuando sale con Wílmar a la calle y este comienza a cometer los crímenes el narrador nos dice: "volvimos a lo de Alexis" (p. 98); usa la misma fórmula para referirse a Alexis y a Wílmar: “...mi niño, Alexis, el único” (p. 113), “...Wílmar, mi niño, el único” (p. 118); los crímenes que comete Wílmar tienen motivaciones baladíes y reciben los aplausos y júbilos de Fernando, tal como ocurrió con los crímenes de Alexis.

Para afianzar este sistema de repeticiones, el narrador de la novela dedica tres páginas a la historia del Nato (pp. 106-109), que parece no tener mayor conexión con la historia central. Fernando no puede creer que el Difunto le esté contando que mataron al Nato, "el tira de Junín que detestaba a los maricas", porque "al Nato sí lo mataron, y ahí, en ese mismo punto del espacio, pero hace treinta años, cuando ni siquiera habían abierto la Avenida Oriental, que era una calle estrecha" (p. 106-107). Fernando sube con Wílmar a Manrique, a la casa del Nato, para comprobar si era el mismo Nato a quien habían asesinado treinta años atrás y, cuando abre el ataúd y ve el cadáver, nos comenta que "en efecto era El Ñato, el mismo hijueputa. Las bolsas bajo los ojos, la nariz ñata, el bigotito a lo Hitler... Igualito. Era porque era. Pero si habían pasado treinta años, ¿cómo podía seguir igual? Ahí les dejo para que lo piensen el problemita" (p. 109). Y remata la historia pensando: "¿No sería que la realidad en Medellín se enloqueció y se estaba repitiendo?" (p. 109). Esta historia de repetición está contenida dentro de la historia Fernando-Wílmar, que es una repetición de la historia Alexis-Fernando. Además, el narrador insiste en ello, obliga a no pasarlo por alto. Subrayo sus palabras: “NNo sería que la realidad en Medellín se enloqueció y se estaba repitiendo?". La pregunta tiene el propósito de marcar el sentido de la historia del Ñato, que no es otro que apuntalar el sistema de repeticiones que define la propuesta estética del texto y orienta su sentido. Ahora bien, el Ñato era un asesino de homosexuales que fue asesinado dos veces y cuya historia se cuenta dentro de la historia de Wílmar, el asesino (que pronto será asesinado) del sicario Alexis. Es la duplicación de una historia violenta dentro de la duplicación de otra historia violenta, un sistema de cajas chinas cuyo eje es la violencia. Esta estructura textual se refuerza con una serie de frases en las cuales el narrador se hace más incisivo y más explícito: "Es que Colombia cambia, pero sigue igual, son nuevas caras de un mismo desastre" (p. 12); "En el momento en que escribo el conflicto aún no se resuelve: siguen matando y naciendo" (p. 28); "Una venganza trae otra y una muerte otra muerte (p. 29). Muy poco de estas estrategias textuales se preservan en la película.

Además, el narrador protagonista de la novela insiste en frases que refuerzan esta idea del ciclo: "Bombay era la misma como yo siempre he sido yo: niño, joven, hombre, viejo, el mimo rencor cansado que olvida todos los agravios por pereza de recordar" (p. 13); "Que mi vida acabe como empezó, con la felicidad del que no lo sabe" (p. 16); "La trama de mi vida es la de un libro absurdo en el que lo que debía ir primero va luego" (p. 17); "Ese río es como yo: siempre el mismo en su permanencia yéndose" (p. 31).

Toda esta cuidadosa y repetida estructura está al servicio de la transmisión de una idea rectora de la novela: la violencia en Colombia es cíclica, es un mismo fenómeno repetido: "es la sangre que derramará Colombia ahora y siempre por los siglos de los siglos, amen" (p. 8), como afirma el narrador en el primer párrafo de la novela. Pero esta idea de la repetición sin fin de la violencia ha sido un lugar común en Colombia desde el siglo pasado. Así lo concluye Daniel Pécaut: "Un buen número de colombianos resultan persuadidos de que la violencia constituye la trama subyacente de su 
historia política y social. Una violencia que, más allá de su materialidad, comanda así un imaginario en el que adquiere la figura de un destino que estaría condenado a repetirse sin fin" "“Reflexiones", pp. 2627). La estructura cíclica del texto, definida en todos estos elementos de repetición está al servicio de tramitar este viejo lugar común sobre la violencia en Colombia. Lugar común que se convierte en la idea rectora de la novela y que define la interpretación de la realidad de la violencia en Colombia que en ella se tramita. La novela sustenta esta tesis de la violencia cíclica y es esta tesis la que define el espíritu apocalíptico del texto y promueve la conclusión de la imposibilidad de salir del desastre. ${ }^{2}$

En la película se sostiene la estructura de repetición diegética de las historias Fernando-Alexis y Fernando-Wílmar, pero, salvo algunos elementos del sistema de contrastes, los otros funcionamientos textuales que soportaban dicha estructura cíclica desaparecen: la identificación de los dos amantes sicarios, las situaciones de repetición, la historia del Nato, las frases del narrador protagonista que insisten en la idea del ciclo, la estructura misma del texto. Disuelta la estructura de duplicación se disuelve la interpretación de mundo que esta estructura comporta, lo que implica que la lectura de la realidad es distinta para los dos textos.

Esta diferencia se hace evidente en un análisis comparativo entre los comienzos y los finales de los dos textos. La novela empieza con una secuencia cuyo centro diegético es la añoranza por el pasado y la desazón por la corrupción del presente. De este contraste temporal se deriva una serie dicotómica de conceptos cuyo propósito es sustentar la idea del desplazamiento del narrador. La secuencia inicial de la película se dedica centralmente a la presentación amorosa entre Fernando y Alexis, y a la presentación de Medellín como una ciudad violenta. Aunque aparece el elemento de la nostalgia en el plano de la cantina "Bombay", el sistema de contrastes es menos fuerte en el texto fílmico. Por ello, mientras que la imagen central en la secuencia inicial de la novela es el globo perdiéndose en el fin del mundo (como la infancia y la felicidad de Fernando), en la película la imagen central es la desnudez de Alexis con una pistola sobrepuesta al pene, como una continuación violenta de su sexualidad. La imagen del globo sintetiza el proyecto estético del texto literario: la añoranza del pasado idílico que refuerza el asco por el presente crapuloso. Es precisamente la desesperanza por el presente y la convicción de estar condenados a su incesante repetición lo que determina al narrador protagonista a optar por una solución genocida. La imagen de la pistola-falo también señala de entrada el centro de interés del texto fílmico: la relación amor y muerte, sexo y violencia, esto es, la pregunta por la experiencia de la pasión

2 Esta misma estrategia textual de repetición diegética define la estructura cíclica de la película En la tormenta de Fernando Vallejo, producida en 1980, catorce años antes de su novela La Virgen de los sicarios. Y esta estructura cíclica tiene la misma función semiótica en los dos textos, esto es, plantear la idea que la violencia en Colombia es un ciclo ineluctable. En la tormenta desarrolla la historia de una doble incursión de grupos armados contra la población inerme. En la primera incursión, los pájaros conservadores atacan una vereda liberal y, después de seleccionar y liberar a los de su mismo partido, asesinan a los del partido Liberal e incendian las casas de la vereda. En la segunda incursión, años después, los chusmeros liberales de Sangre Negra atacan una chiva (autobús intermunicipal) y, después de seleccionar y liberar a los de su partido, asesinan a los del partido Conservador y queman la chiva. De la primera masacre ejecutada por los conservadores sobrevive un niño, quien antes de huir ve a su hermanita de tres o cuatro años atrapada por el fuego. Ese niño es uno de los chusmeros que ataca la chiva en la segunda incursión. En esa segunda incursión también sobrevive un niño que antes de huir ve como su hermanita de tres o cuatro años es atrapada por el fuego. Esta escena final claramente indica que el niño se convertirá en asesino, que la historia se va a repetir, que el ciclo fatal de violencias se continuará en él. La recurrencia a una misma propuesta narrativa orientada por una misma idea sobre la violencia en dos textos de soportes expresivos tan distintos como los del cine y la novela, cuyas historias remiten a dos períodos de violencia distintos y con una diferencia temporal de más de una década, da cuenta de la persistencia de esa interpretación de la realidad del autor y de inmutabilidad de la visión de mundo que orienta sus creaciones. 
amorosa en el escenario de una ciudad degradada en la violencia. Los dos comienzos, entonces, entrañan la divergencia del proyecto estético-ético entre los dos textos.

Ocurre lo mismo en lo atinente a los finales. En la novela, el narrador se despide afirmando que se va a subir en cualquiera de esos buses, lo que implica una estructura abierta y por lo tanto la posible continuación del ciclo. En la película, la imagen final es un plano general de Fernando cerrando las cortinas de su apartamento y un fundido al negro, con el fondo musical de la canción "Senderito de amor". Todo el plano refuerza la idea de la pena amorosa y la imposibilidad de seguir adelante. Es claramente un plano de clausura narrativa que no deja lugar a pensar en una estructura abierta o en la posibilidad de la repetición.

Si la estructura cíclica define el proyecto estético en la novela y es ancilar a la idea de que la violencia en Colombia es un ciclo que se repite sin cesar, una especie de sino trágico, la supresión de dicha estructura en el filme implica que hay una radical diferencia en la configuración del proyecto estético en cada texto. Esta divergencia se hace ostensible en el análisis de otros elementos de la textualidad.

\section{Narrador y pensamien- to criminal}

Hay una enorme diferencia en lo atinente al número de crímenes, la calidad de las víctimas y las actitudes de Fernando respecto de los asesinatos. Si se compara la primera secuencia de la novela - tan poética, tan eficaz en el uso del procedimiento del contraste, tan prometedora en la caracterización de los personajes- con el resto de la novela - $\tan$ irregular en los contrastes, tan entregada a la recreación homicida, tan plana en la definición de sus personajes-, se podría pensar que a partir de la página 37 todo se reduce a una fatigante acumulación de frases repulsivas y de crímenes absurdos, que se alivianan con algunas referencias amorosas y los juegos de lenguaje. ${ }^{3} \mathrm{Y}$ el narrador parece deleitarse en ello: "Y sigamos con los muertos que a eso es a lo que vinimos" (p. 62). Fernando parece diluirse en esa complicidad gozosa y en esa lengua feroz; el personaje duplicado Alexis-Wílmar se limita a ser una extensión, armada y asesina, de los aparentes desvaríos $y$ del furor verbal del anciano amante; Medellín queda reducida a ser una "puta perra paridora" de homicidas, indigentes y pobres.

En el filme, Alexis mata a ocho hombres, ninguna mujer, ningún niño. Un número muy inferior a los 35 homicidios recreados en la novela. Además, en el texto fílmico se ofrece, previamente, una justificación a cada crimen: cuatro de las víctimas de Alexis son sicarios que intentaron asesinar primero a los dos protagonistas; los dos hombres del metro y el taxista trataron de agredir a Fernando antes de que Alexis reaccionara. Wílmar, por su parte, mata a un hombre (cinco menos que en la novela), el silbador, que ha tratado de sacar el arma para dispararles a ellos y que resulta ser el atracador asesino del comienzo de la película. Es decir, hay una justificación de estos crímenes con el recurso a la defensa propia. Incluso, cuando José Antonio Vázquez habla de Alexis en el filme dice que es un sicario que "tiene sobre su conciencia tres o cuatro muertos" (00:06:55), mientras en la novela se habla de diez asesinatos cometidos por Alexis antes de que conociera a Fernando. Claramente, la disminución del número de crímenes, la justificación de los mismos, la supresión de los asesinatos de mujeres, de mujeres embarazadas y de niños (además de la lista que hace Fernando de los crímenes innumerables de Wílmar) da cuenta de un complejo proceso de adaptación cuyo propósito es, en principio, evitar el cansancio del espectador y dis-

3 Es tan fatigante esta abultada recreación de crímenes que los críticos no se ponen de acuerdo a la hora de determinar las cifras: para el caso de los asesinatos de Alexis, Erna Von der Walde, en "La sicaresca colombiana", suma quince; Carvajal cuenta 35; José Osorio aproxima “más de cien”. Yo coincido con Carvajal: son 35. 
minuir la sanción moral sobre Fernando y sobre sus amantes sicarios. Carvajal destaca este procedimiento: "También se debe decir que esta idea de mermar la carga emocional de las muertes se ve reflejada claramente en la película cuando se 'evitan' todas las muertes de niños que se producen en la novela" (2004, p. 66, nota 13). Esto genera, en palabras de José Osorio: "Un cambio importante en la postura del ethos que va de la novela a la película con respecto a este tipo de muertes" (2010, sin número de página). El cambio destruye, además, un procedimiento textual fundamental en la poética del texto escrito: la acumulación. La recreación reiterada de los crímenes es uno de los procedimientos textuales más eficaces en el propósito de visibilizar la violencia en la novela y busca golpear al lector, enfrentarlo a la violencia hasta saturarlo. La destrucción de este procedimiento de acumulación en el texto fílmico indica una importante transformación respecto del principio ético-estético de la novela, y modifica la percepción del lector-espectador.

De la misma manera, la actitud de Fernando respecto de estos asesinatos es totalmente distinta. La muerte del taxista provoca una mirada reprobadora de Fernando en el texto fílmico, mientras que en la novela se admira la "espléndida explosión" del carro. En el filme, el asesinato de dos hombres que intentan agredir a Fernando en el metro ${ }^{4}$ hace que Fernando le aconseje a Alexis que "antes de disparar recapacita, cuenta hasta diez" (00:42:44) y le enseña el quinto mandamiento: ¡No matarás! En la novela, la muerte de la empleada de la cafetería se banaliza con el comentario del narrador, según el cual hay que volver al sitio del crimen porque allí se almuerza muy bien; en el texto fílmico Fernando detiene a Alexis cuando va a tomar el arma y evita el crimen. En el filme, ante el asesinato del punkero, Fernando reacciona alarmado: " $A$ Ay, niño, qué hiciste!”, “Matar a ese pobre muchacho por nada! ¿Cómo pudiste?" (00:33:06), "me siento culpable, niño" (00:34:52), "ya van siete noches" (00:35:06); mientras que en la novela Fernando observa a la gente que se acerca a mirar el cadáver y afirma: "Estaban ellos más contentos que yo" (p. 27). En tanto que en la novela Fernando hace la feliz contabilidad de los 250 asesinatos de su amante, en la película reconviene a Alexis: “¿Niño, qué está pasando? ¿Adónde hemos llegado? Todos estos muertos absurdos. Me remuerde la conciencia. ¿Cuántos llevamos?”
(00:55:41). La persistencia de la culpa en Fernando, que no lo deja dormir, revela un carácter diametralmente opuesto al del narrador de la novela, quien, por el contrario, celebra los crímenes con expresiones de júbilo.

Esto se refuerza en el filme con la ausencia notable de los asesinatos de niños y mujeres embarazadas y la supresión, en consecuencia, de las celebraciones de dichas muertes y de los comentarios burlones de Fernando. Pero no sólo se suprime la burla del protagonista respecto de esas muertes sino en relación con casi todos los crímenes que cometen sus amantes. Hay que precisar que, en el texto fílmico, Fernando reacciona con indolencia $\mathrm{O}$ festivamente ante algunos de estos crímenes, pero esto es sólo en el caso de los sicarios que tratan de asesinarlos: insulta al muerto que le salpica de sangre la casa de la infancia y se ríe de la imitación de la mujer embarazada que hace Alexis después de asesinar al sicario que trató de matarlo. Sin embargo, ni siquiera en estos casos, Fernando aplaude o festeja los crímenes.

Como se ve, la comisión de los asesinatos está justificada en el filme de muchas maneras y, además, las reacciones de Fernando son sanciones

4 Como explica Carvajal, esta escena es una transposición del pasaje de la novela en el cual son asesinados la mujer y los niños en el bus. 
morales, pues, como él mismo declara, está "contra toda violencia" (00:18:35) y, por eso, "simplemente no hay que andar armados" (00:35:26). Esto, unido al sentimiento de culpa que Fernando expresa reiteradamente por los asesinatos cometidos por sus amantes, a su intento de aleccionarlos y a la ausencia de los festejos del narrador protagonista por estos crímenes, indica que los dos personajes Fernando -el de la novela y el del film- tienen una concepción diferente sobre la vida humana. Estos procedimientos de atenuación y de supresión aligeran la carga de odio de Fernando, le dan un carácter menos repulsivo en el texto fílmico y le construyen una dimensión moral distinta.

\section{La diatriba del narrador y el llamado al genocidio}

En la esfera de las valoraciones de mundo y del discurso de Fernando en cada texto también encontramos posiciones radicalmente distintas. En la novela, Fernando señala que la comunidad de la cual él mismo ha salido adolece de una lamentable condición étnica y cultural: "No hay plaga mayor sobre el planeta que el campesino colombiano, no hay alimaña más dañina, más mala. Pedir y pedir, matar y morir, tal su miserable sino" (pp. 8384). Y ofrece una explicación de carácter etno-histórico, según la cual esta condición étnica pervertida es producto del cruce de razas ocurrido en la conquista y durante la colonia: "De mala sangre, de mala raza, de mala índole, de mala ley, no hay mezcla más mala que la del español con el indio y el negro: producen saltapatrases o sea changos, simios, monos, micos con cola para que con ella se vuelvan a subir al árbol" (p. 90). Esta condición le produce un rechazo profundo: "Me avergüenzo de esta raza limosnera" (p. 15) y ofrece una solución genocida para el problema: "Esta es una raza ventajosa, envidiosa, rencorosa embustera, traicionera, ladrona: la peste humana en su más extrema ruindad. ¿La solución para acabar con la juventud delincuente? Exterminen la niñez" (pp. 27-28). Además, como una de las expresiones de esta perversión étnica y cultural es la pobreza, insiste en una fórmula genocida dirigida a quienes están en situación de pobreza: "Mi fórmula para acabar con ella [la pobreza] no es hacerles casa a los que la padecen y se empeñan en no ser ricos: es cianurarles de una vez por todas el agua y listo" (p. 68), "Mi fórmula para acabar con la lucha de clases es fumigar a esta roña [los pobres]" (p. 96), "Por razones genéticas el pobre no tiene derecho a reproducirse" (p. 104). Como los elementos centrales de esta reproducción, que reproduce la raza y la pobreza, es la mujer y la niñez, la emprende contra los niños: "La niñez es como la pobreza, dañina, mala" (p. 106), y contra las mujeres a quienes las califi- ca de "putas perras paridoras" (p. 64) o "perra humana embarazada" (p. 101). En estas sentencias del narrador se devela un pensamiento genocida, una misoginia radical y un profundo desprecio por el otro y por la vida humana.

Además de la explicación étnica del talante del colombiano necesariamente inclinado a la violencia y al desorden, el narrador protagonista construye un diagnóstico del problema de la violencia en Colombia que pasa por la argumentación en torno a la incapacidad de las instituciones reguladoras y su influencia en la formación de una sociedad anómica, y la descripción y registro del desarrollo violento y desordenado de las comunas de Medellín y de su lenguaje. Este diagnóstico es coherente con la idea que define la estructura de la novela, según la cual la violencia colombiana es cíclica y los colombianos estamos condenados a padecer sin fin este fenómeno. Fernando considera que si la disposición a la violencia está en nuestra definición identitaria, en nuestra esencia ontológica y en nuestros genes (de razas ya inferiores y más debilitadas en su cruce), y, además, las instituciones no funcionan, los colombianos no tenemos salida de la violencia y la descomposición social. Esta constatación le permite al narrador protagonista insistir reiteradamente en la solución que a él le parece la única posible: aniquilar a 
los pobres. Así se completa el proyecto ético-estético de la novela, que está definido por un pensamiento criminal. ${ }^{5}$

Este diagnóstico y la solución propuesta son consecuentes con el desarrollo argumental del texto, que gira en torno al crimen, esto es, a la materialización de las ideas genocidas del narrador. Claudia Ospina anota: "Se propone en esta novela una fórmula genocida como solución al conflicto y caos reinantes que sólo llevan al exterminio total de su región y, por extensión, de su país" (2010, p. 164). Felipe Oliver llega a una interpretación similar: "Después de que todos los relatos políticos, religiosos, económicos, etcétera, han ido cayendo uno detrás de otro, ¿no es acaso un acto de necedad creer en algo que no sea la extinción de la especie? Se trata de una postura desde luego radical, pero en esta exageración reside el encanto de Vallejo" (2007, p. 50). No obstante, es inquietante el aplauso final del crítico. Oliver deriva el placer ético y estético que le produce la novela de Vallejo de la propuesta de solución crimi- nal de Fernando, que apenas le parece una exageración radical. Ética y estéticamente esto me resulta inaceptable.

En el texto fílmico, por el contrario, la mayoría de estas sentencias se suprimen y las muy pocas que perviven son las menos feroces, algunas de ellas incluso mutiladas de su agresividad inicial o atenuadas por el contexto de enunciación y por el talante menos agresivo que le da al personaje la caracterización del actor ${ }^{6}$. Por ejemplo, ante la pregunta de si le gustan las mujeres, Fernando responde que "depende de los hermanitos que tenga". Ese chiste popular es igual en los dos textos, pero el narrador protagonista de la novela pasa inmediatamente del chiste a la frase "en serio": "Para mí las mujeres es como si no tuvieran alma. Un coco vacío. $\mathrm{Y}$ que por eso con ellas es imposible el amor" (p. 18). La película suprime estas palabras, tan importantes en el texto escrito para la configuración de las características misóginas del narrador protagonista. La supresión de estos contenidos misóginos reduce la ofen- siva acción de Fernando a un mero chiste popular y ayuda a consolidar el carácter juguetón del personaje fílmico y a mejorar su empatía con el espectador. La actuación refuerza este carácter, pues la sentencia se enuncia lúdicamente, con una sonrisa traviesa, despojándose así de los tintes nocivos que tiene en el texto escrito. Este procedimiento de supresión y de recontextualización torna en algo positivo un rasgo profundamente repudiable en el texto de origen.

\section{Eros y Thanatos}

A la par con la transformación del personaje Fernando y de la atenuación de su pensamiento criminal, la historia de su pasión amorosa se potencia en la película. Aunque en la novela el narrador indica clara y repetidamente que evitará cualquier descripción de sus noches apasionadas con los sicarios, el texto fílmico se deleita en ellas. Ya en la primera secuencia del filme se ofrece un plano general con marco de espejo en el que los amantes se solazan en un acto sexual explícito, con intercambio de

5 Un desarrollo más exhaustivo de este tema lo hago en mi libro "La Virgen de los sicarios" y la novela del sicario en Colombia.

6 La caracterización que hace Germán Jaramillo de Fernando suaviza la carga negativa de sus acciones: voz cálida, picardía gestual, talante mesurado, maneras armónicas, sonrisa permanente, vestimenta modesta e informal. Otro elemento importante en este proceso de atenuación es la risa y la festividad con las que el sicario amante celebra las ocurrencias de Fernando, pues lo inscribe dentro del código del humor y vuelve al personaje un individuo más amable.

7 Estas son escenas tremendamente provocadoras en el contexto de una sociedad como la colombiana, tan conservadora en asuntos sexuales y con una casi nula experiencia en el cine queer. A propósito de estos planos, Fernández L'Hoeste comenta: "Explicit representations on the large screen, however, were still a remote event. Thus the personification of the world of sicarios -which in and by itself was an uncomfortable topic for many Colombians- contributes to an expansion in the construction of national identity in more than one way" (p. 550). Estas escenas fueron decisivas para que cierto sector de la intelectualidad colombiana expresara furiosos juicios negativos sobre La Virgen de los sicarios, en un hecho por demás vergonzoso dada la calidad de la discusión y la precariedad de las argumentaciones. No me detengo en las particularidades de esta discusión, pero señalo que el escándalo benefició la exposición al público tanto del filme como de la novela. 
posiciones. También aparecen, más adelante, tomas que desarrollan el encuentro sexual de Fernando con Wílmar. Además aparecen primeros planos de besos apasionados de Fernando con los amantes? Lo mismo sucede con las frases de amor que ellos intercambian. En la novela, esas frases ocurren en contextos casi siempre portadores de un mensaje desafiante que relativiza su intención afectiva: ante la Virgen o en una iglesia (pp. $15,94)$, en frases cargadas de misoginia (p. 19) o desprecio por la familia o la comunidad (pp. 24-25, 30, 40, 45), o ante el crimen (pp. 25-26, 28, 71). En la película, en cambio, cobran una gran relevancia. Así ocurre después de la escena del asesinato de los sicarios frente a la mujer embarazada. Los amantes se encuentran en el apartamento y Alexis, con una almohada bajo la camisa, imita burlescamente los gritos desesperados de la mujer ante los cadáveres. La escena termina en un primer plano en el que los amantes se miran a los ojos y Fernando dice muy conmovido: "Alexis, niño, eres lo más hermoso que me ha dado la vida" (00:59:40). El sentimiento de la voz se realza con música suave de piano y una luz plena del sol que destaca los gestos de los amantes, la cámara se mueve a su alrededor dándole un gran dinamismo al plano mientras los amantes se besan apasionadamente. El contexto de la frase arranca en la situación del crimen, como ocurre en la novela, pero en la película rápidamente se desprende de este contexto y crea otro más íntimo, que refuerza la intensidad de las palabras y la seriedad de la declamación del amante viejo. De hecho, en la novela las declaraciones amorosas no las dirige el narrador protagonista a sus amantes sino a su narratario, y son un desafío.

Otro mecanismo a través del cual se realza la historia de la pasión amorosa en la película es la idea del sacrificio. En la escena de la muerte de Alexis, ellos van caminando por la avenida cuando Alexis ve aproximarse a los sicarios. Como ha perdido el arma en el caño, el muchacho no puede defenderse y sólo atina a alertar a Fernando, llamándolo por su nombre por primera vez, e interpone su cuerpo para que las balas no alcancen el cuerpo del amante viejo. Alexis recibe todos los impactos de los proyectiles y muere sacrificándose por Fernando. Alexis también previene a Fernando en la novela, pero ni se interpone ni se construye la idea del sacrificio, que es tan eficaz en la consolidación de la historia amorosa y la eleva a primer plano del texto fílmico.

El duelo por Alexis es esencial también para señalar el predominio de la pasión amorosa en el texto fílmico. En el texto literario pasan menos de cuatro semanas desde la muerte de Alexis hasta que
Fernando encuentra un nuevo amor. Fernando conoció a Alexis un lunes de diciembre, poco después de la muerte de Pablo Escobar, ocurrida el 2 de diciembre de 1993 (p. 61). Debe de haber sido muy pocos días después, porque antes de que se acabara el año nos ha detallado veinticuatro asesinatos de Alexis (pp. 64-65). Cuando Alexis fue asesinado, los amantes llevaban siete meses juntos (p. 82), es decir, este deceso ocurrió en julio de 1994. Cuando Fernando conoció a Wílmar todavía estaba el mismo presidente César Gaviria (p. 89), cuyo relevo se daría el 7 de agosto de 1994. Durante estos pocos días de duelo Fernando visitó a la madre de Alexis para dejarle algún dinero y para averiguar por el nombre del asesino. Los pocos párrafos que se concentran en la experiencia del duelo son cortados por páginas que se dedican a hacer una radiografía de Medellín y de sus comunas de odio. Sólo al final del pasaje, Fernando narra el sueño en el cual se ve en la iglesia, rodeado de mendigos y viciosos, y nos habla de su dolor. Completamente diferente es lo que ocurre en el filme. Cuando Fernando salió de su duelo había ocurrido el cambio de gobierno y ya se había posesionado el presidente Ernesto Samper Pizano. Es decir, pasaron meses antes de que Fernando lograra alguna normalidad y se encontrara con Wílmar. Esto da cuenta de la intensidad del 
sentimiento que le produjo la pérdida de Alexis. La escena del duelo ocupa varias tomas y tiene una duración de diez minutos (1:40:00 - 1:50:00), lo que indica su importancia dentro del filme. Además de los signos exteriores de dolor de Fernando (llanto, barba sin rasurar, rostro descompuesto), la intensidad del dolor se enfatiza con el recurso de una cámara acelerada para indicar el paso inclemente del tiempo que cierra la escena. Toda la secuencia sirve para expresar el dolor de Fernando por la muerte del amante. Incluso cuando visita a la familia de Alexis, el dolor se materializa en unos planos de los ríos de sangre que se forman con la lluvia y de la imagen de laguna azul donde muere la alegría de Fernando. Después Fernando aparece barbado, abotagado, transido de dolor en el Patio del Tango y durante un sueño en el que se ve llorando desconsoladamente en el piso de la iglesia que se funde a un plano de Fernando llorando en la mesa del comedor en su apartamento. Incluso en otra secuencia, la de la consolidación del amor entre Fernando y Wílmar, cuando los dos amantes entran por primera vez al apartamento de Fernando, la cámara detalla basuras, papeles, botellas regadas por todo lado. Este desorden riñe con el carácter del personaje y manifiesta los signos de su dolor. José Osorio destaca la importancia para la caracterización del personaje de este énfasis en el duelo que se hace el texto fílmico: "Este lapso mayor de tiempo concentra en la mirada del espectador una mayor sensación del dolor que ha significado en Fernando la muerte de Alexis; lo hace más humano en este sentido, menos cínico frente al dolor" (2010, sin número de página).

La preminencia de la historia amorosa sobre la violenta está ilustrada en el plano de la desnudez de Alexis en el cuarto de las mariposas, durante la primera secuencia del filme. Alexis se desnuda por orden de Fernando. En un plano general en interior se destacan la figura recortada de Fernando $\mathrm{y}$, al fondo, la figura completa de Alexis bajo una tenue luz. Alexis tiene el revólver en la mano derecha y el arma está sobrepuesta al pene. Atrás y al lado izquierdo de Alexis hay una escultura del Arcángel San Miguel y una pared llena de relojes. Alexis se mueve hacia la mesa de noche y deja el arma para acostarse a retozar con el hombre que se convertirá en su amante. Estos planos son especialmente potentes, porque ponen de relieve los elementos centrales del texto fílmico: la juventud del sicario y la vejez del amante (claras alusiones a las nociones de vida y muerte, que la realidad de la violencia sicarial troca: el viejo vive, el joven muere); la figura religiosa del Arcángel alusiva al Apocalipsis, que simboliza la violencia de Medellín y la resolución del exterminio; los planos detalle de los escapularios y del revólver, que aluden a dos rasgos definitorios de la figura del sicario: el fetichismo religioso y la violencia; los relojes, en alusión al tiempo - en la novela, suspendido; en la película, dinámico-; El penerevólver que conjuga sexo y violencia ${ }^{8}$. La secuencia y la imagen remiten a la dicotomía freudiana Eros y Thanatos, plenamente encarnada en la figura del amante niño: el sicario está al servicio de la realización de los deseos sexuales de Fernando, así como de la materialización de sus impulsos criminales. Esta doble condición del sicario para el amante viejo es la misma para los dos textos. Sin embargo, en la película la escena del arma pene culmina cuando Alexis deja el revólver sobre la mesa y se acuesta a esperar a su amante, lo que indica que en esta conjunción entre la violencia y el sexo se privilegia la pasión amorosa:

8 Refiriéndose al sentido de esta imagen del arma sobrepuesta a los genitales del sicario, Gastón Alzate plantea que "la construcción social de la masculinidad para muchos jóvenes colombianos, sea esta heterosexual u homosexual y aunque muchos se nieguen a reconocerlo está mediatizada por las armas. Alexis se cubre el sexo con 'el fierro' como símbolo de esta construcción simbólica masculina” (p. 9). Creo que esta potente imagen no se agota en su referencia cultural a la masculinidad armada, sino que está al servicio de la compleja conjunción violencia y sexo, o muerte y amor, o Eros y Thanatos, que es el constructo simbólico rector del texto fílmico. 
la toma cierra con un plano de fondo cuyo encuadre es un espejo que refleja la imagen de los amantes entregados al deleite de sus cuerpos. La preeminencia de la dimensión sexual sobre la violenta orienta de manera definitiva el proyecto estético del filme en una dirección opuesta al de la novela.

Esto se refuerza con los planos finales de la película. Aparece Fernando corriendo las cortinas del apartamento y el fundido al negro mientras suena "Senderito de amor", que es una canción que expresa el profundo sentimiento por la pérdida del amor. De esta manera se refuerza el sentimiento de desolación profundo que le provoca a Fernando la pérdida del amante. Esa canción ya se ha escuchado al comienzo de la película. Cuando Fernando y Alexis visitan Sabaneta, la escuchan mientras se toman un aguardiente en la cantina Bombay y a Fernando le causa tal conmoción que lo hace desplomarse en llanto sobre la mesa. Esa canción simboliza para Fernando la pérdida definitiva de la familia, del pasado, de la felicidad. Al repetirse en la secuencia final del filme, la canción, que ya viene con toda esa carga de contenidos, hace que la pérdida de los amores y de la felicidad del pasado remoto se conjuguen con la pérdida del amor reciente, para transmitir una sensación final de desesperanza absoluta.

Otros elementos del texto literario que se suprimen en el proceso de adaptación al texto fílmico son: la historia de las comunas, la explicación étnica de la violencia y su carácter cíclico, la historia de la "degeneración" de un lenguaje mutado en "argot" en los sectores marginados. Contrario a las parrafadas dedicadas en la novela al proceso de degradación de Medellín y su lenguaje, en la película sólo se hace referencia a esa descomposición en la masa de pobres y maleantes que se amontonan en la iglesia que sueña Fernando y en los planos de la visita a la casa de la madre de Alexis, que, con una ocularización interna de Fernando, detallan la miseria de la vivienda. La perspectiva del odio, que hacen coincidir en la novela las imágenes del duelo con las patéticas imágenes de las comunas, se tramita en la película a través la sentencia del hermanito de Alexis, que con más o menos 10 años de edad, ya jura vengar la muerte de su hermano. Es decir, el filme renuncia a dar explicaciones de ningún tipo sobre las determinaciones históricas y culturales, y sobre los procesos sociales que condujeron a la violencia en Medellín. Esta desatención por estos as- pectos, que son fundamentales a la novela y que explican el odio del narrador protagonista y la violencia de sus sicarios, indica, de nuevo, la divergencia del proyecto ético-estético del filme respecto del de la novela.

La pasión amorosa, tanto en la novela como en la película, es lo único que satisface a Fernando y le ofrece algún sentido a su existencia. Todo lo demás le parece despreciable en esa Medellín llena de pobres, de sicarios y de ruido. Ahora bien, mientras la novela privilegia la historia de la violencia, el filme privilegia la historia de la pasión amorosa: en el texto fílmico se cuenta una historia de amor y sexo duplicada, en el contexto de una ciudad violenta; la novela es una densa historia de violencias, con algún alivio en la pasión amorosa. Esta inversión determina profundas diferencias en los dos textos. El tremendo engranaje argumental, ideativo y estructural que en la novela está al servicio de un sistema de pensamiento criminal, prácticamente desaparece en el texto fílmico. A través de procesos de atenuación (disminución, supresión o realce) de elementos sustanciales al texto literario, el filme se despoja de ese sistema de pensamiento $y$ construye una mirada sobre Medellín que, filtrada por la experiencia amorosa, resulta menos abrumadora. 


\section{Referencias}

Alzate, G. "El extremismo de la lucidez: San Fernando Vallejo." Revista Iberoamericana 79.222 (2008): 1-17. 10 oct. 2011.

Carvajal Córdoba, E. "La Virgen de los sicarios: Entre el encanto literario y la frustración fílmica." Estudios de Literatura Colombiana 15 (2004): 51-78.

Fernández L'Hoeste, H. "From Rodrigo to Rosario: Birth and Rise of the Sicaresca.” Revista de Estudios Hispánicos 42 (2008): 543-57. 18 sept. 2011.

Jácome Liévano, M. R. La novela sicaresca: exploraciones ficcionales de la criminalidad juvenil del narcotráfico. Diss. The University of Iowa, 2006. 20 nov. 2010.

Oliver, F. “Después de García Márquez: Tres aproximaciones a la novela urbana colombiana.” Revista de Humanidades 23 (2007): 41-6. 19 jul. 2011.

Osorio, J. "La Virgen de los sicarios y la adaptación cinematográfica”. Letralia 219 (2009). 20 sept. 2010.

Osorio, Ó., (2013), La Virgen de los sicarios y la novela del sicario en Colombia. Cali: Secretaría de Cultura.

Ospina, C. Representación de la violencia en la novela del narcotráfico y el cine colombiano contemporáneo. Diss. University of Kentucky, 2010.12 nov. 2011.

Pécaut, D., (2001), "Reflexiones sobre la violencia en Colombia." Violencia, guerra y paz. Una mirada desde las ciencias sociales. Trad. Anthony Sampson. Cali: Universidad del Valle.

Schroeder, B., (2000), La Virgen de los sicarios. Colombia/Francia: Les Films du Losange et-al. DVD.

Vallejo, F., (1998), La Virgen de los sicarios. Colombia: Alfaguara.

Vallejo, F., (1980), En la Tormenta. México. DVD.

Walde Uribe, E. "La sicaresca colombiana. Narrar la violencia en América Latina." Nueva Sociedad 170 (2000): 222-27. 17 mayo 2011. 